\title{
The oesophageal Doppler monitor
}

\author{
A safe means of monitoring the circulation
}

$\mathrm{T}$

The oesophageal Doppler monitor, described in the early $1970 \mathrm{~s}^{1}$ and subsequently refined by Singer, ${ }^{2}$ provides a safe and minimally invasive means of continuously monitoring the circulation. A paper in this week's issue describes using the oesophageal Doppler monitor to guide intraoperative fluid resuscitation in elderly patients undergoing repair of proximal femoral fractures (p 909). ${ }^{3}$ These patients are typically managed with only minimal intraoperative monitoring, and the paper thus raises questions about the role of invasive intraoperative monitoring. Similar questions have recently been raised about the role and use of pulmonary artery catheters. ${ }^{4}$

The oesophageal Doppler monitor measures blood flow velocity in the descending thoracic aorta using a flexible ultrasound probe about the size of a nasogastric tube. When combined with a nomogram based estimate of aortic cross sectional area (derived from the patient's age, height, and weight), it allows haemodynamic variables, including stroke volume and cardiac output, to be calculated. Despite several potential sources of error, there is good correlation, at least in adults, between measures of cardiac output made simultaneously with the oesophageal Doppler monitor and conventional thermodilution. ${ }^{256}$

In contrast to the pulmonary artery catheter, the probe of an oesophageal Doppler monitor can be inserted within minutes, requires minimal technical skill, and is not associated with major complications. ${ }^{7}$ In our experience the probe may be safely left in situ for over two weeks. The monitor should not, however, be regarded as a replacement for a pulmonary artery catheter. It cannot provide direct measurement of pulmonary artery and pulmonary artery occlusion pressures (though changes in the corrected systolic flow time, measured by the oesophageal Doppler monitor, have been shown to reflect qualitative changes in pulmonary artery occlusion pressures, allowing optimisation of left ventricular filling ${ }^{8}$ ). Also, the turbulent aortic blood flow associated with use of the intra-aortic balloon pump and in aortic coarctation causes the oesophageal Doppler monitor to be unreliable in these settings.

In the study by Sinclair et al patients given intravascular colloid as guided by the oeosphageal Doppler monitor had a significantly reduced (44\%) hospital stay compared with controls, but too few were studied to make any useful assessment of differences in postoperative morbidity and mortality. ${ }^{3}$ Nevertheless, this study adds to the growing body of evidence supporting the notion that early goal directed resuscitation reduces both morbidity and mortality after surgery. ${ }^{9-11}$ Applying the $44 \%$ reduction in hospital stay to the 57000 patients undergoing femoral fracture repair in Britain each year ${ }^{12}$ translates into 450000 patient hospital days. Extrapolating beyond Britain is harder: in America, for example, lengths of stay are already shorter. At Duke University Medical Centre 103 patients underwent repair of proximal femur fractures in 1996. The median length of hospital stay was 6 days (range 2-45), in contrast to 18 days in the control group in Sinclair and other's study. Mortality in hospital was 3\%. Of the survivors, however, only $37 \%$ were discharged home. The rest were discharged to skilled nursing facilities, and among these patients the length of stay and the proportion who eventually returned home is not known.

In light of the recent debate on the safety and efficacy of pulmonary artery catheters, could the oesophageal Doppler monitor be a viable alternative? Although it is not known how often pulmonary artery catheters are used perioperatively-though over 2 million are sold each year world wide ${ }^{13}$ - they are probably used less often in Britain than in America. ${ }^{14}$ Despite the absence of large, randomised trials unequivocally showing efficacy, pulmonary artery catheters remain the de facto standard for invasive cardiovascular monitoring, and it will be interesting to see what effect the widely endorsed consensus statement from the US Society of Critical Care Medicine has on their use. ${ }^{4}$ This rejected the idea of a moratorium on the use of pulmonary artery catheters but recommended randomised controlled trials for most indications. Our belief is that in the perioperative period the oesophageal Doppler monitor can be used as an alternative to the pulmonary artery catheter.

A second question is whether the oesophageal Doppler monitor has a place in the intraoperative management of patients who would not normally be monitored with either a central venous pressure monitor or a pulmonary artery catheter? While most anaesthetists in Britain would agree that some means of optimising the circulation in high risk surgical patients would be desirable, the evidence suggests that many of these patients receive no invasive monitoring. Of the 1802 patients investigated by the National Confidential Enquiry into Perioperative Deaths 73\% were classified as American Society of Anesthesiology physical status grade III or above, ${ }^{15}$ but direct monitoring of arterial, central venous, and pulmonary artery pressure was used in $24 \%, 31 \%$, and $4 \%$ of cases respectively. Unfortunately this type of study cannot determine if 
perioperative monitoring improves patient outcome. The oesophageal Doppler monitor undoubtedly offers a safe means of monitoring the circulation, though it has failed to attain widespread use. Larger studies in a variety of settings will have to show both efficacy and cost effectiveness if this form of monitoring is to become established as a routine component of perioperative care.

Tong Joo Gan Assistant professor

Joseph E Arrowsmith Visiting associate

Department of Anesthesiology, Duke University Medical Center, Durham, NC 27710, USA

1 Side CD, Gosling RJ. Non-surgical assessment of cardiac function. Nature 1971;232:335-336.

2 Singer M, Clarke J, Bennett ED. Continuous hemodynamic monitoring by esophageal Doppler. Crit Care Med 1989;17:447-452.

3 Sinclair S, James S, Singer M. Intraoperative intravascular volume optimisation and length of hospital stay after repair of proximal femoral fracture: randomised controlled trial. BMJ 1997;315:909-12.

4 Pulmonary artery catheter consensus conference participants. Pulmonary artery catheter consensus conference: consensus statement. Crit Care Med 1997;25:910-925.
5 Klotz KF, Klingsiek S, Singer M, Wenk H, Eleftheriadis E, Kuppe H, et al. Continuous measurement of cardiac output during aortic crossclamping by the oesophageal Doppler monitor ODM-1. Br J Anaesth 1995;74:655-660.

6 Nakatsuka M, Fisher RA, Ham JM, Searman DS, Posner MP. Validation of the esophageal Doppler cardiac function monitor with the standard thermodilution method during liver transplantation. Anesth Analg 1997;84:SCA51.

7 Singer M. Esophageal Doppler monitoring of aortic blood flow: beat-bybeat cardiac output monitoring. Int Anesth Clin 1993;31:99-125.

8 Singer M, Bennett ED. Non-invasive optimization of left ventricular filling by esophageal Doppler. Crit Care Med 1991;19:1132-1137.

9 Boyd O, Grounds RM, Bennett ED. A randomized clinical trial of the effect of deliberate perioperative increase in oxygen delivery on mortality in high-risk surgical patients. JAMA 1993;270:2699-2707.

10 Mythen AR, Webb AR. Intra-operative gut mucosal hypoperfusion is associated with increased post-operative complications and cost. Intens Care Med 1994;20:99-104.

11 Mythen MG, Webb AR. Perioperative plasma volume expansion reduces the incidence of gut mucosal hypoperfusion during cardiac surgery. Arch Surg 1995;130:423-429.

12 The Audit Commission. United they stand. Co-ordinating care for elderly patients with hip fracture. London: HMSO Publications, 1995.

13 Ginosar Y, Sprung CL. The Swan-Ganz catheter. Twenty five years of monitoring. Crit Care Clin 1996;12:771-776.

14 Singer M, Bennett ED. Invasive hemodynamic monitoring in the United Kingdom. Enough or too little? Chest 1989;95:923-626.

15 National Confidential Enquiry into Perioperative Deaths. The Report of the National Confidential Enquiry into Perioperative Deaths. London: NCEPOD, 1996.

\title{
Attention deficit hyperactivity disorder
}

\author{
There is no easy answer on whether to medicate or not
}

A syndrome that was described by the ancient Greeks and has been widely observed by physicians since then is likely to have considerable face validity, but there continues to be disagreement about the diagnosis, cause, prevalence, and treatment of attention deficit hyperactivity disorder. ${ }^{1}$ From the beginning of this century the concept of the condition has evolved from it being a biologically based disorder of behaviour control, from a condition with minimal brain dysfunction, to a disorder characterised by a deficit of attention. ${ }^{2}$ The main controversy now is about how to treat the condition.

The past 20 years have seen the development of diagnostic criteria in both Britain and America. In 1981 the criteria of the Diagnostic and Statistical Manual version III (DSM-III) departed from those of the International Classification of Diseases ninth edition (ICD-9) in creating subtypes of attention deficit disorder with and without hyperactivity. Meanwhile, the ICD-9 continued to emphasise "pervasive hyperactivity" as the hallmark of the so called hyperactive syndrome. Now, however, DSM-IV and ICD-10 research criteria for attention deficit hyperactivity disorder and hyperkinetic disorder are almost identical, showing a rapprochement between American and British approaches.

Theories of aetiology have also evolved, influenced by advances in brain imaging. The current view is that there is dysfunction of prefrontal and subcortical striatal areas of the brain that are implicated in inhibition of irrelevant responses and executive functions. ${ }^{3}$ Twin studies suggest high heritability of the disorder, ${ }^{4}$ while a recent molecular genetic study suggests a possible relation with the $\mathrm{D} 4$ receptor gene. ${ }^{5}$ Important questions remain about the relation of the disorder to language and learning disability at the phenotypic and genetic level; and the phenotype may have broadened to include children with learning disability.

Approaches to treatment have also progressed. An important advance was the use of systematic behaviour modification techniques in the management of disruptive classroom behaviour. ${ }^{6}$ In America and Australia, however, management has been characterised by an increasing use of stimulant medications such as methylphenidate and dexamphetamine, with $3-5 \%$ of primary schoolchildren treated in some American states. Many studies have shown positive effects of stimulant medication in most children diagnosed with attention deficit hyperactivity disorder. ${ }^{78}$ Concerns about addiction have not proved justified, and if the drugs are properly prescribed side effects are not a major concern, although morbidity in terms of appetite, dysphoria, headache, and tics should be carefully monitored. ${ }^{9}$

Public concern about overuse of medications has alternated with increasing parental demands for treatment for the disorder. The apparent differences in the use of stimulant drugs between Europe and America have been commented on, but differences of similar magnitude exist within countries, certainly within America and Australia. ${ }^{10}{ }^{11}$ Many clinicians in both Britain and America have remained committed to environmental explanations of behaviour and have been loath to use drugs. Additionally, disputes over whether attention deficit hyperactivity disorder is a specific abnormality or merely the extreme end of a range of behaviour have clouded the issue. Nevertheless, when DSM-IV or ICD-10 criteria are used for case selection, significant numbers of the school aged population benefit from careful use of stimulant drugs. Use of these drugs improves not only school performance but often family and social functioning as well. ${ }^{12}$ 
A recent report from Michigan shows that the percentage of boys aged 10-11 years being treated with stimulant drugs was $3-5 \%$, with considerable variation between counties. ${ }^{11}$ Primary care physicians wrote $84 \%$ of prescriptions, while paediatricians wrote $59 \%$ of prescriptions for patients younger than 20 years. A similar report from Australia indicates a significant increase in stimulant use between 1988 and 1993, with wide variation between states and territories. ${ }^{10}$ These data suggest that these paediatricians and primary care physicians have taken a pragmatic approach, tending to fill the void left by their more cautious mental health colleagues. Nevertheless, the widespread use of drugs for this condition by paediatricians, and in some places by general practitioners, raises questions about whether they are adequately aware of, or trained in, behavioural therapies or, indeed, in pharmacotherapy.

The role of general practitioners should be more clearly defined in screening for attention deficit hyperactivity disorder. The DSM-IV or ICD-10 based screening instruments should be made available for use by general practitioners. In Australia the National Health and Medical Research Council has produced a useful working party report on the condition, which establishes a multidisciplinary policy. The draft report emphasises the use of appropriate rating scales, as well as multiple sources of information including parents, caregivers, professionals, and especially teachers. ${ }^{13}$

The promise of advances from genetic and brain imaging methods will require a continued and expanded multidisciplinary effort. Meanwhile, whether to treat the condition with drugs will be determined by the complex interactions of cultural norms, medical manpower, and parental expectations.

\section{Florence Levy Senior staff specialist}

Prince of Wales Hospital, University of New South Wales, Randwick, New South Wales 2031, Australia

1 Husain SA, Cantwell DP. Fundamentals of child and adolescent psychiatry. Washington, DC: American Psychiatric Press, 1991

2 Douglas VI. Stop, look and listen: the problem of sustained attention and impulse control in hyperactive and normal children. Can J Behav Sci $1972 ; 4: 259-82$

3 Castellanos FX, Giedd JN, Marsh WL. Quantitative brain magnetic resonance imaging in attention deficit hyperactivity disorder. Arch Gen Psychiatry 1996;53:607-16.

4 Levy F, Hay D, McStephen M, Wood C, Waldman I. Attention deficit hyperactivity disorder: a category or a continuum? Genetic analysis of a largescale twin study. J Am Acad Child Adolesc Psychiatry 1997:36:737-4.

5 La Hoste GJ, Swanson JM, Wigal SB, Globe C, Wigal T, King N, et al. Dopamine $\mathrm{D} 4$ receptor gene is associated with attention deficit hyperactivity disorder. Molecular Psychiatry 1996;1:121-4.

6 O'Leary KD, Pelham WE, Rosenbaum A, Price GH. Behavioural treatment of hyperkinetic children: an experimental evaluation of its usefulness. Clin Pediatrics 1996;15:510-5.

7 Barkley RA. A review of stimulant drug research with hyperactive children. Arch Gen Psychiatry 1977;18:137-65.

8 Elia J, Borcherding BG, Rapoport JL. Methylphenidate and dextroamphetamine treatments of hyperactivity: are there true nonresponders? Psych Res 1991;36:141-55.

9 Barkley RA, McMurray MB, Edelbrook CS, Robbins K. Side effects of methylphenidate in children with attention deficit hyperactivity disorder: a systematic placebo-controlled evaluation. Pediatrics 1990;86:184-92.

10 Valentine J, Zubrick S, Sly P. National trends in the use of stimulant medication for attention deficit hyperactivity disorder. J Paediatr Child Health 1996;32:223-7.

11 Rappley MD, Gardiner JC, Jetton JR, Houng RT. The use of methylphenidate in Michigan. Arch Pediatr Adolesc Med 1995;149:675-9.

12 Barkley RA, Cunningham CE. The effects of methylphenidate on the mother-child interactions of hyperactive children. Arch Gen Psychiatry 1979;36:201-8.

13 Australian National Health and Medical Research Council. Report of working party on ADHD. Canberra: Australian Government Publishing Service, 1996.

\section{France seeks to curb health costs by fining doctors}

\section{Heavy handed and expensive}

See p 943

I $\mathrm{n}$ happier times of economic growth, most Western governments had a light touch in controlling health care costs. But as the growth of health care spending has outstripped the performance of most economies since the 1970 s, health care payers have realised the need to act more firmly. They face powerful groups with an interest in resistance: health care providers, who gain from increased income.

Fortunately some tools are available to help targeting costs at health care, doctors, and patient level. At the "system" level the most effective is a limit on overall annual expenditure. Britain is a good example of this: health care spending has grown less than in almost all other Western countries since the 1970s. But while this method controls overall costs, it does little to relieve pressures on the budget. Other tools are needed, such as controlling the number of doctors; paying providers capitation fees rather than fees for service; and having primary care providers acting as gatekeepers to secondary care.

At a more micro-level are tools to change the behaviour of the chief spenders-doctors. The carrots include guidelines, peer pressure, and financial incentives to operate within a budget; the stick is sanctions when rules are not followed. Tools to influence patient behaviour include user charges. If all these do not work fast enough governments can relieve pressure on budgets through other means-for example, in Britain by redefining services off the NHS menu (such as eye tests) or allowing waiting lists for care to grow.

Governments are constrained by the combination of tools they inherit and their ability to introduce new ones. In this respect the French have some strengths-notably, almost universal coverage of health benefits paid for mainly by government. This provides the government with leverage over health care providers, and it has been used successfully to cap hospital expenditures. But, as Durand-Zaleski et al explain in this issue, outside the hospital sector their leverage is weaker: there is no global budget; doctors get fees for service; there are no curbs on prescription drugs, diagnostic tests, or procedures; there are no gatekeepers; and patients can shop around to their heart's content (p 943). ${ }^{1}$

Faced with the unsurprising growth of costs in this area, the French government offered various carrots to change clinical behaviour (guidelines) and user charges for patients. It ducked fundamental reform of the system, such as paying doctors on a capitated basis; giving them a fixed budget; encouraging patients to register with a primary care doctor; or controlling 
the numbers of doctors. But since the carrots have not worked, France has now taken up the stick. DurandZaleski et al describe a system introduced in 1994 in which doctors practising outside hospital must either follow national rules for prescribing, ordering diagnostic tests, and carrying out procedures, or be fined. ${ }^{1}$

These rules have had some impact. The growth in costs for services outside hospital slowed from $6 \%$ to $2.3 \%$. Savings on prescriptions alone were estimated at $£ 34 \mathrm{~m}$. Of 13000 doctors surveyed, 75 were eventually fined. ${ }^{1}$ However, the impact on health has not yet been evaluated. Furthermore, the cost of policing doctors in this way is likely to be expensive and may even outweigh the savings made: a reviewer took over 300 hours to check prescriptions ordered by one doctor over two months.

Are there lessons for the NHS and other health systems? A fundamental issue in controlling costs is how far various methods should be targeted on the health care system itself, doctors, or patients. A secondary question concerns the best tools to use. Historically in the NHS the system has been targeted-for example, through the use of a global budget, controls on staff numbers, and through the gatekeeper arrangement in primary care. These have proved highly effective, but while there is still more to do at this level, ${ }^{2}$ attention has increasingly been focused on changing doctors' behaviour.

First came professionally led activities such as guidelines and clinical audit, but these have not yet had much effect on, for example, drug costs. ${ }^{3}$ Next came government incentives such as giving doctors budgets to manage. These have not had great success either, ${ }^{45}$ possibly because both incentives and sanctions are weak or because considerations of cost currently conflict too obviously with the professional ethos. ${ }^{6}$ As yet few initiatives have targeted the behaviour of individual doctors directly using rules and sanctions, as in managed care organisations in America. ${ }^{7}$ The French experience described in this issue suggests that this is likely to be expensive.

Finally, should patients be targeted through user charges? User charges are costly to administer and penalise the sick. Furthermore, until adequate steps have been taken to tackle the health system and clinical behaviour, it is unfair to penalise patients, whose decisions are largely not responsible for health care costs. This message should ring loud and clear from all organisations (like the BMA) whose members are advocates for patients. Either way the main lesson from France is for the medical profession: take more responsibility for costs, or be increasingly managed until the sticks become unavoidable.

Jennifer Dixon Fellow in policy analysis

King's Fund Policy Institute, London W1M 0AN

1 Durand-Zaleski I, Colin C, Blum-Boisgard C. Preliminary evaluation of an attempt to merge mandatory practice guidelines and cost containment in France. BMJ 1997;315:9-20.

2 Dixon J, Harrison A. A little local difficulty? BMJ 1997;314:216-9.

3 Bloor K, Maynard A. Lessons from international experience in controlling pharmaceutical expenditure II: influencing doctors. BMJ 1996;312:1525-7.

4 Buxton M, Packwood T, Keen J. Final report of the Brunel University evaluation of resource management: summary. Uxbridge: Brunel University, 1991.

5 Dixon J, Glennerster $\mathrm{H}$. What do we know about fundholding in general practice? BMJ 1995;311:727-30.

6 Berwick DM. Medical associations: guilds or leaders? BMJ 1997;314:296-8.

7 Kongstvedt PR. Changing provider behaviour in managed care plans. In: Kongstvedt PR, ed. Essentials of managed health care. Gathersburg, MD: Aspen Publications, 1995.

\section{An inspectorate for the health service?}

\section{Ofsthealth may be inevitable, but it needs to observe the science of quality improvement}

I magine yourself being listed for a day case procedure, organising work and home around the date, arriving anxiously at the ward only to be turned away. The reason? Your body mass index does not meet that hospital's criteria. This happened last week to one of our patients. The clinical decision may have been correct but the process of care failed. It is the cumulative effect of such instances together with knowledge of the wide variation that exists in clinical outcomes for similar cohorts of patients ${ }^{12}$ that has led to political demands for an office of standards in health (Ofsthealth)-an inspectorate of health services linked to the development of national standards, similar to that which exists for education. ${ }^{3}$

Inequalities in access to care, the experience of that care, and the outcomes associated with it are just as unacceptable as inequalities in resource distribution. The cost of poor quality is a haemorrhage of scarce resources, largely untracked and ignored in the cry for more money for the NHS. The ambition to place quality at the core of the NHS is, therefore, impeccable.

Many will argue that this has already been done. Certainly directors of quality have sprung up in the last few years, and many useful initiatives have taken place. Equally, many schemes have faded rapidly and died. This, together with jargon from management consultants inviting hard pressed staff to "share the quality vision," has devalued the currency of quality within the NHS. Meanwhile, the royal colleges have generated clinical quality standards and defended vigorously any territorial incursions. Management is left largely to focus on non-clinical issues.

Such distinctions are irrelevant to patients. They experience and judge the whole process of care and all its elements. It is the interaction between the parts, not just the individual performance of one of them, that ensures the quality of the process. The system of quality management in the NHS is endemically fragmented-professionally, managerially, and organisationally. The failures and frustrations that have resulted have in turn led to the calls for an Ofsthealth.

The process of care experienced by a patient has three outcomes: clinical outcomes, service or satisfaction outcomes, and cost outcomes. If we measure just one, what is the evidence that this gives us information 
about the others, or allows us to improve the process as a whole? In America, the performance based culture, publication of mortality rates has been abandoned by Medicare. It changed clinical behaviour in a way that was not in the best interests of patients-fostering, for example, an unwillingness to operate on higher risk patients. ${ }^{45}$ In Britain the measurement of finished consultant episodes (the NHS's measure of hospital activity) and associated costs gives no indication of how patients have fared or the appropriateness of the process that yielded the data: it too has generated perverse incentives. In these circumstances individuals' energy is directed to fulfilling the standard laid down for one part of the process, irrespective of the overall effect.

During the past decade a growing body of evidence worldwide has shown that a combination of improved clinical outcomes, increased patient satisfaction, and decreased costs can be achieved by considering whole processes. Dramatic changes can be brought about in these measures, thus releasing the substantial resources that are used in providing poor quality. The organisational requirements are well documented. ${ }^{6}$ Briefly what is needed are clear aims, a culture and management system that permits data examination without fear, and rigorous statistical measurement of a care process across traditional boundaries. Such changes, and their beneficial effects, have occurred in places in Britain (such as Leicester Royal Infirmary), but those organisations are isolated pockets of enthusiastic activity.

Therein lies the problem. We know that lasting quality improvement is best managed from the "inside out." Currently this relies on organic growth stimulated by local innovators. How do we encourage the critical mass that ensures adoption by the mainstream in a way that matches the speed of public demand and political requirement? Do national standards and an inspectorate play a part?

Isolated standards can distort behaviour and reduce the dynamics of quality improvement. ${ }^{7}$ Inspec- tion systems can generate fear and a punitive climate, creating an unwillingness to examine data openly. ${ }^{8}$ Yet Ofsted, the inspection body for education, has certainly tapped a need in educational consumers and created a feeling of involvement and choice. In health, patients are increasingly able to access sources of information about their diseases, including clinical guidelines from the internet. The government rightly focuses on the experience of patients and their clinical outcome. The "pull" effect of this on quality is gathering pace and will increase when people realise the cost benefits of getting the process right first time.

Do the professions need the catalyst of an Ofsthealth to move faster from the heritage of individualism? ${ }^{9}$ Do clinicians and managers need that encouragement to place the science of process central to their activity on quality? Perhaps so. For certain, we clinicians cannot operate in a vacuum, hiding statistical variation behind the shibboleth of clinical freedom and reinforcing the illusion that we are the sole arbiters of care.

\section{John Oldham General practitioner}

Manor House Doctors' Surgery, Glossop, Derbyshire SK13 8PS Dr Oldham is a general practice advisor to the NHS Executive, but the views expressed here are entirely his own.

1 Anderson TF, Mooney G, eds. The challenge of medical practice variation. London:Macmillan, 1996.

2 Rethams JJ, Saebu L. Do general practitioners act consistently in real practice when they see the same patient twice? Examination of intradoctor variation using standardised (simulated) patients. BMJ 1997; 314:1170-3.

3 Building on the best of the NHS. London: Liberal Democrats, 1995.

4 Thomsom RG, McElroy H, Kazandjian VA. Maryland Hospital Quality Indicator project in the UK: an approach for promoting continuous quality improvement. Quality in Healthcare 1997;6:49-55.

5 McKee M. Indicators of clinical performance. BMJ 1997;315:142.

6 Batalden PB, Stolz PK. A framework for the continuous improvement of health care, building and applying professional and improvement knowledge to test changes in daily work. Joint Commission Journal on Quality Improvement 1993;19:424-47.

7 McLaughlin CP, Kaluzny AD. Total quality management in health: making it work. Health Care Management Review 1990;15:7-14

8 Berwick D. Continuous improvement as an ideal in health care. New Eng JMed 1989;320:53-6.

9 Berwick D. Medical associations: guilds or leaders? BMJ 1997;314:1564-5.

\section{Every system is designed to get the results it gets}

\section{So taking only one element out of it may not improve anything}

$\mathrm{P}$ atients and public assume that the surgeon is responsible for the quality of surgical care and that they are protected from substandard care by quality monitoring conducted by professional bodies. These bodies are often presented with evidence suggesting suboptimal clinical care and rule on its validity. Such is the case of a cardiothoracic surgeon from Bristol who has been cited for having unacceptably poor results which comes before Britain's regulatory body, the General Medical Council, next week (in a case expected to last four months). These cases occur with some frequency and often concern high visibility specialties with easy to count outcomes. Yet causal attribution is difficult since most clinicians provide care in complex settings over which individuals exert only limited control.

In cardiac care the skills of the anesthesiologist, perfusionist, cardiac intensive care nurse, and others also affect the outcomes of care. Their individual competence is not sufficient: they must also work well together. It is the product of their individual work-not the sum-that the patient experiences. Removing one "outlier" surgeon from practice will, at most, influence the second decimal place of the national cardiac surgery mortality rate. It may be necessary for the public welfare that we do this, but the public should not be led to believe that such actions do much to improve the quality of care or reduce the risk of cardiac surgery. Furthermore, we must be aware of the predictable and pernicious effect of this action on other practitioners, who may feel that "there but for the grace of God go I."

Much of the controversy that swirls around quality monitoring has to do with its methods. Assessing the outcomes of clinical care is difficult and relies on the methods of observational epidemiology. The primary 
threats to the validity of observational studies are chance, bias, and confounding. ${ }^{1}$ Each plays a potentially important role in measuring the outcomes of cardiac surgery. Random variability is important in rare outcomes. If a cardiac surgeon performs 140 coronary bypass procedures in a year there will, on average, be four deaths (2.9\% mortality rate). The $95 \%$ confidence interval extends from 0.8 to $7.2 \%{ }^{2}$ The imprecision of the estimate will be even greater for surgeons who do fewer procedures. One solution to sparse data is to aggregate results over a longer period, yet this may obscure important time related effects. The use of control charts, which allow us to differentiate between sampling related variability and actual process change may help in monitoring quality. ${ }^{3}$ Bias is systematic error in the data. Discipline and the enthusiastic participation of clinicians will be required to yield accurate datasets. Confounding is a distortion of observed mortality rates brought about by differences in case mix. This is perhaps the most debated aspect of assessing the outcomes of clinical care, though it may not deserve as much attention as the complex system of causation that produces a clinical outcome.

If chance, bias, and confounding are dealt with successfully the result will be a valid measurement system. In fact, with respect to the mortality associated with coronary artery surgery, there is relatively secure science. This is evidenced by consensus on important risk variables ${ }^{4}$ and good performance of most multivariate risk models. ${ }^{5}$ When cardiac surgery centres have been carefully examined substantial variability in the processes of care $^{6}$ and clinical outcomes $^{78}$ has been found. Indeed, it would be surprising if it were not, given the variation in organisation, training, experience, habit, and setting. In this variability we will find the clues to improved clinical care. Improvement entails examining flawed systems and interactions among people as well as individual competencies.

These observations then guide redesign of the processes of care. Without redesign, the same system and processes that have created the current reality will work together to repeat it, even if a single participant is removed. Many barriers to genuine quality improvement originate in the craftsman type organisation of clinical care. Individual practitioners are expected to keep abreast of advances, attend to the details of clinical care, and learn from their experience. The responsibility is clearly placed but the infrastructure is often inadequate to accomplish the task. The relative isolation of clinical practice, the lack of trusted real time clinical measurement systems, and the difficulty of learning from the few adverse outcomes that do occur in actual practice are important barriers to improving clinical practice.

We have gained some experience in developing an infrastructure for improving the quality of cardiac surgery in Maine, New Hampshire, and Vermont. All cardiac surgeons in this region contribute data on every case. The datasets are validated regularly, and reports are distributed and discussed three times a year. Specific studies and site visits by multidisciplinary teams ${ }^{9}$ are used to generate and test hypotheses and effect changes in the processes of care. ${ }^{10}$ The participation of clinicians for over a decade has confirmed that they care deeply about the quality of care. We have developed a regional infrastructure to examine processes, to use data for improvement, and to learn from daily practice. We have learnt from Deming, ${ }^{11}$ Shewhart, ${ }^{12}$ Berwick, ${ }^{13}$ and Nelson and Batalden ${ }^{14}$ that there are certain prerequisites for this type of activity. Foremost is a safe place to work. The data necessary to improve clinical care cannot be used to punish individuals who participate in the quality improvement efforts. We also need an agreed metric for outcomes and a forum to discuss results. The number of adverse outcomes in the experience of any particular clinician is simply too small to inform decisions. Lastly, we need comparative knowledge of the processes of care associated with outcomes so that clinicians can learn from each other. In our experience, this process has been multidisciplinary, scientifically rigorous, inexpensive, and enjoyable.

Continual improvement of health care is a goal shared by society, payers, and clinicians. It is essential for the public good that clinicians assume responsibility for improving the quality of clinical care. They have unique knowledge of clinical reasoning and processes, are most appropriate to render opinion on the adequacy of clinical care, and have traditionally assumed the role of patient advocates. Sustained incremental improvement will require leadership by professional societies in each specialty and commitment to develop the necessary infrastructure. This approach holds great potential to save lives, improve functional health status, and increase the efficiency of clinical care. The focus on inspection of individual outcomes and punishment may occasionally be necessary to protect public safety, but it is not enough genuinely to improve health care.

\section{Gerald T O'Connor Professor of Medicine and of Community and Family Medicine}

Center for the Evaluative Clinical Sciences, Dartmouth Medical School, Hanover, NH 03755-3863, USA

1 Hennekens CH, Buring JE. Epidemiology in medicine. Boston: Little, Brown, 1988.

2 Fleiss JL. Statistical methods for rates and proportions. New York:John Wiley, 1973.

3 Wheeler DJ. Advanced topics in statistical process control. The power of Shewhart's charts. Knoxville, Tennessee: SPC Press, 1995.

4 Report of the Ad Hoc Committee on Risk Factors for Coronary Artery Bypass Surgery. Ann Thorac Surg 1988;46:348-9.

5 Jones RH, Hannan EL, Hammermeister KE, DeLong ER, O'Connor GT, Luepker RV, et al. and participants in the Working Group Panel on the Cooperative CABG Database Project. Identification of preoperative variables needed to risk adjust short-term mortality after coronary artery bypass grafting. JACC 1996;28:1478-87.

6 Tobler HG, Sethi GK, Grover PL, Shroyer AL, Moritz TE, Henderson WG, et al. Variations in processes and structures of cardiac surgery practice. Medical Care 1995;33 (suppl):0S43-58.

7 Hannan EL, Kilburn H, O'Donnell JF, Lukacik G, Shields EP. Adult open heart surgery in New York State. An analysis of risk factors and hospital mortality rates. JAMA 1990;264:2768-74.

8 O'Connor GT, Plume SK, Olmstead EM, Coffin LH, Morton JR, Maloney CT, et al. A regional prospective study of in-hospital mortality associated with coronary artery bypass grafting. JAMA 1991;266:803-9.

9 Kasper JF, Plume SK, O'Connor GT. A methodology for QI in the coronary artery bypass grafting procedure involving comparative process analysis. Quality Review Bulletin 1992;18:129-33.

10 O'Connor GT, Plume SK, Olmstead EM, Morton JR, Maloney CT, Nugent WC, et al. A regional intervention to improve the hospital mortality associated with coronary artery bypass graft surgery. JAMA 1996;275:841-6.

11 Deming WE. Out of the crisis. Cambridge, Massachusetts: Massachusetts Institute of Technology, Center for Advanced Engineering Study, 1986.

12 Shewhart W. Statistical method from the viewpoint of quality control. New York: Dover, 1986.

13 Berwick DM. Continuous improvement as an ideal in health care. $N$ Engl J Med 1989;320: 53-6.

14 Nelson EC, Batalden PB. Patient based quality measurement systems. Quality Management in Health Care 1993;2:18-30. 